\title{
Intraocular inflammation after proton beam irradiation for uveal melanoma
}

Livia Lumbroso, Laurence Desjardins, Christine Levy, Corine Plancher, Eric Frau,
François D'Hermies, Pierre Schlienger, Hamin Mammar, Sabine Delacroix,
Catherine Nauraye, Régis Ferrand, Claire Desblancs, Alexandre Mazal, Bernard Asselain

Abstract

Aim-To describe the inflammatory reaction that can occur following proton beam irradiation of uveal melanomas based on a large series of patients and to try to determine the risk factors for this reaction.

Methods-Data from a cohort of patients with uveal melanoma treated by proton beam irradiation between 1991 and 1994 were analysed. The presence of inflammation was recorded and evaluated. KaplanMeier estimates and statistical analysis of general and tumour related risk factors were performed.

Results-28\% of patients treated during this period presented with ocular inflammation (median follow up 62 months). Risks factors were essentially tumour related and were correlated with larger lesions (height $>5 \mathrm{~mm}$, diameter $>12$ mm, volume $>0.4 \mathrm{~cm}^{3}$ ). Multivariate analysis identified initial tumour height and irradiation of a large volume of the eye as the two most important risk factors. Ocular inflammation usually consisted of mild anterior uveitis, resolving rapidly after topical steroids and cycloplegics. The incidence of inflammation after proton beam irradiation of melanomas seems higher than previously reported and is related to larger lesions. Evidence of inflammation associated with uveal melanoma has been described and seems to be associated with tumour necrosis (spontaneous or after irradiation). The appearance of transient inflammation during the follow up of these patients may be related to the release of inflammatory cytokines during tumour necrosis.

Conclusion-Inflammation following proton beam irradiation is not unusual. It is correlated with larger initial tumours and may be related to tumour necrosis. (Br F Ophthalmol 2001;85:1305-1308)

Proton Beam Therapy Centre, Orsay, France

H Mammar

$S$ Delacroix

C Nauraye

R Ferrand

C Desblancs

A Mazal

Correspondence to: Laurence Desjardins, MD, Ophthalmology Department, Institut Curie, 26 rue d'Ulm, 75005 Paris, France

laurence.desjardins@curie.net

Accepted for publication 28 March 2001 been described after charged particle irradiation for uveal melanoma, including eyelid damage, sicca syndrome, keratitis, cataract, optic neuropathy, radiation retinopathy, neovascular glaucoma, and phthisis. ${ }^{9-11}$ Some of them can lead to secondary enucleation even in the absence of local recurrence.

Another, rarely reported, side effect is the appearance of an inflammatory reaction of the treated eye, usually consisting of anterior uveitis. Only limited data are available on this complication with few data from large patient series.

We decided to study the development of this side effect during the follow up of patients treated in our institution with proton beam therapy for uveal melanoma. We tried to isolate the general and tumour related risk factors at the time of diagnosis, and to describe the course of this inflammation.

\section{Materials and methods}

This series includes patients treated for uveal melanoma in our institution with proton beam radiotherapy since 1991 with a minimum follow up of 5 years.

The database recorded the general and tumour related characteristics at baseline, and data from the proton beam therapy computerised program.

All patients received proton beam irradiation after surgical insertion of tantalum clips to mark the tumour margins. The irradiation protocol consisted of 60 Gy equivalent cobalt administered in four fractions including the tumour and $2.5 \mathrm{~mm}$ safety margins.

Patients were reviewed in our institution 1 month after irradiation and then every 6 months for 3 years, then yearly. An examination by the referring ophthalmologist was performed every 3 months. A complete functional assessment was performed annually in our clinic. The parameters recorded during this examination included visual acuity, presence of lid damage, keratitis, presence of cataract, glaucoma, optic neuropathy, or radiation retinopathy. The patient was also specifically examined for signs of ocular inflammation (active or sequelae). Active inflammation was defined by the presence of anterior or posterior uveitis (presence of cells and flare in the anterior chamber and/or vitreous). Sequelae of inflammation were defined as the presence of pigmented keratic precipitates and/or posterior synechiae.

We searched the database of treated patients to identify those presenting intraocular inflammation (active or sequelae) on at least one follow up examination and tried to identify any tumour control, but may be associated with ocular complications. Several side effects have 


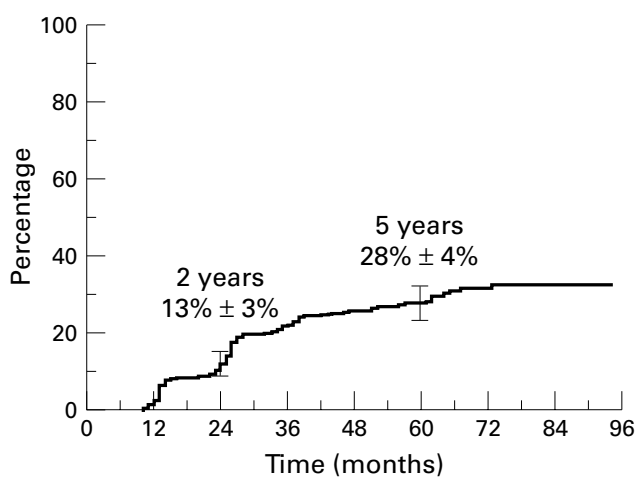

Figure 1 Kaplan-Meier curve for the development of inflammation after proton beam irradiation.

risk factors: general and tumour related characteristics (tumour diameter, height, volume, site) as well as irradiation parameters and the doses received by the various ocular structures. We used Kaplan-Meier estimates to study the incidence of ocular inflammation at each follow up assessment.

The effect of each individual clinical variable on the incidence of ocular inflammation was then analysed by univariate analysis and variables presenting a statistically significant correlation were then submitted to multivariate analysis with the Cox model.

Table 1 Tumour related risk factors

\begin{tabular}{|c|c|c|c|c|c|}
\hline Variable & No & No & Yes & $p$ Value & $R R$ \\
\hline Right eye & 227 & 158 & 69 & NS & 1.4 \\
\hline Left eye & 208 & 161 & 47 & & 1 \\
\hline \multicolumn{6}{|l|}{ Tumour site } \\
\hline Anterior & 33 & 19 & 14 & \multirow[t]{3}{*}{$<0.0001$} & 3.1 \\
\hline Involving equator & 186 & 117 & 69 & & 3.01 \\
\hline Posterior & 215 & 182 & 33 & & 1 \\
\hline \multicolumn{6}{|c|}{ Tumour site (posterior) } \\
\hline No & 220 & 137 & 83 & \multirow[t]{2}{*}{$<0.0001$} & 3.01 \\
\hline Yes & 215 & 182 & 33 & & 1 \\
\hline \multicolumn{6}{|l|}{ Tumour diameter } \\
\hline$\leqslant 12 \mathrm{~mm}$ & 247 & 210 & 37 & \multirow[t]{2}{*}{$<0.0001$} & 1 \\
\hline$>12 \mathrm{~mm}$ & 188 & 109 & 79 & & 3.7 \\
\hline \multicolumn{6}{|l|}{ Tumour height } \\
\hline$\leqslant 5 \mathrm{~mm}$ & 229 & 207 & 22 & \multirow[t]{2}{*}{$<0.0001$} & 1 \\
\hline$>5 \mathrm{~mm}$ & 206 & 112 & 94 & & 6.2 \\
\hline \multicolumn{6}{|l|}{ Tumour volume } \\
\hline$\leqslant 0.4 \mathrm{~cm}^{3}$ & 233 & 212 & 21 & \multirow[t]{3}{*}{$<0.0001$} & 1 \\
\hline $0.4-1.00 \mathrm{~cm}^{3}$ & 115 & 67 & 48 & & 5.8 \\
\hline$>1 \mathrm{~cm}^{3}$ & 86 & 39 & 47 & & 10.2 \\
\hline \multicolumn{6}{|l|}{ Retinal detachment } \\
\hline No & 333 & 260 & 73 & \multirow[t]{2}{*}{$<0.0001$} & 1 \\
\hline Yes & 102 & 59 & 43 & & 2.2 \\
\hline
\end{tabular}

Table 2 Dose related risk factors (20\% of the total dose

\begin{tabular}{|c|c|c|c|c|c|}
\hline Variable & No & No & Yes & $p$ Value & $R R$ \\
\hline \multicolumn{6}{|l|}{$\%$ of retina } \\
\hline$\leqslant 35 \%$ & 262 & 216 & 46 & \multirow{2}{*}{$<0.0001$} & 1 \\
\hline$>35 \%$ & 172 & 102 & 70 & & 2.9 \\
\hline \multicolumn{6}{|c|}{ Volume of eye } \\
\hline$\leqslant 3 \mathrm{~cm}^{3}$ & 245 & 221 & 24 & \multirow[t]{2}{*}{$<0.0001$} & 1 \\
\hline$>3 \mathrm{~cm}^{3}$ & 189 & 97 & 92 & & 7.09 \\
\hline \multicolumn{6}{|c|}{$\%$ of ciliary body } \\
\hline$\leqslant 40 \%$ & 250 & 222 & 28 & \multirow[t]{2}{*}{$<0.0001$} & 1 \\
\hline$>40 \%$ & 184 & 96 & 88 & & 6.2 \\
\hline \multicolumn{6}{|c|}{$\%$ of optic disc } \\
\hline$\leqslant 40 \%$ & 261 & 190 & 71 & \multirow[t]{2}{*}{ NS } & 1.08 \\
\hline$>40 \%$ & 173 & 128 & 45 & & 1 \\
\hline \multicolumn{6}{|c|}{$\%$ of macula } \\
\hline$\leqslant 50 \%$ & 222 & 150 & 72 & \multirow[t]{2}{*}{0.0007} & 1.6 \\
\hline$>50 \%$ & 212 & 168 & 44 & & 1 \\
\hline \multicolumn{6}{|c|}{$\begin{array}{l}\text { Length of optic } \\
\text { nerve }\end{array}$} \\
\hline$\leqslant 1 \mathrm{~mm}$ & 282 & 209 & 73 & \multirow[t]{2}{*}{ NS } & 1 \\
\hline$>1 \mathrm{~mm}$ & 152 & 109 & 43 & & 1.05 \\
\hline
\end{tabular}

The patients' clinical charts were reviewed to retrospectively analyse the clinical features of active ocular inflammation.

\section{Results}

For the study period (September 1991 to December 1994), 480 eyes of 480 patients were treated by proton beam therapy (median follow up 62 months). The tumour was situated posterior to the equator in $46.5 \%$ of cases, touched the equator in $45.8 \%$ of cases, and was anterior to the equator in $7.5 \%$ of cases. Data were not available for one patient. Retinal detachment was present in $26.2 \%$ of cases. The ciliary body was involved in $4.8 \%$ of tumours.

The mean tumour diameter was $12.6 \mathrm{~mm}$ with a median of $12 \mathrm{~mm}$ (range 3-24 mm). The mean tumour height, measured by ultrasound, was $6 \mathrm{~mm}$ (median $5.2 \mathrm{~mm}$; range $1.2-$ $14 \mathrm{~mm}$ ). The mean tumour volume was $0.64 \mathrm{~cm}^{3}$ (median $0.4 \mathrm{~cm}^{3}$; range $0.10-3.67$ $\left.\mathrm{cm}^{3}\right)$.

Local control of the tumour was achieved in $96 \%$ of cases during the follow up period. Secondary enucleation was required for $12 \%$ of treated eyes. Metastatic disease was observed in $24.2 \%$ of patients.

We examined cases of inflammation recorded at each follow up visit comprising functional assessment. Functional assessment data were available for 435 patients of the study population. Twenty four patients died, 14 were enucleated, and seven were lost to follow up. The incidence of inflammation during follow up is shown on the Kaplan-Meier curve (Fig 1). Thirteen per cent of treated eyes presented an episode of inflammation at 2 years and $28 \%$ at 5 years.

Univariate analysis was then performed to identify risk factors for the development of inflammation. General risk factors (age at diagnosis, sex, and side) were not significantly correlated with the development of inflammation. Tumour characteristics were all highly significant (Table 1). Tumours situated anteriorly to the equator or involving the equator presented a higher risk than posterior tumours. The volume of the eye receiving a dose of at least 20 Gy and irradiation of a high percentage of the ciliary body were also highly significant. Irradiation therapy data and the doses of irradiation delivered to ocular structures were also highly significant (Table 2).

The major risk factors identified by Cox multivariate analysis were essentially the initial tumour height and the volume of the eye irradiated.

Seven per cent of eyes developed neovascular glaucoma associated with the inflammatory reaction of the anterior segment, but none of the patients with inflammation alone required secondary enucleation. During the same period $43(9.9 \%)$ patients presented with neovascular glaucoma.

CLINICAL FEATURES OF OCULAR INFLAMMATION We then retrospectively analysed the charts of the 16 patients seen in our institution with active inflammation. All patients presented 
mild anterior uveitis with flare ++ and cells ++ . Posterior synechiae were present in all cases. Intraocular pressure was raised in four patients. A mild anterior vitreous inflammatory reaction (cells + or ++ ) was observed in three patients. One half of these patients were asymptomatic (no ocular complaints) and ocular inflammation was only discovered at the routine follow up examination.

Treatment modalities included topical dexamethasone and a cycloplegic for all patients. Some patients required treatment for raised intraocular pressure. A good response of the anterior chamber inflammatory reaction to treatment was observed within a few days for all cases, often leaving posterior synechiae.

\section{Discussion}

Ocular inflammation was present in $28 \%$ of treated eyes. The incidence curve shows a certain lag between treatment and the onset of inflammatory signs. Inflammation can occur up to 5 years after proton beam therapy. This result differs from other published results on charged particle irradiation and their side effects, in which inflammation is only rarely described, if at all. ${ }^{24}$ Our results appear to indicate that this side effect is not an uncommon feature during follow up of these patients. It is noteworthy that, in our cohort, inflammation was often not diagnosed during the active phase, but only at the stage of sequelae. This could be due to the fact that the patient generally experiences very little discomfort and rarely reports any complaints during the active phase. The clinical features consist of mild anterior uveitis that responds well to local treatment. All these characteristics suggest that intraocular inflammation is rarely a major problem in the follow up of melanoma patients, especially compared with the metastatic potential of the disease or with more serious ocular complications, such as neovascular glaucoma.

Risk factors are tumour dependent, as described for other complications associated with charged particle irradiation-cataract and neovascular glaucoma. ${ }^{911}$ The development of intraocular inflammation is correlated with larger lesions and irradiation of a larger volume of the eye.

Ocular inflammation and choroidal melanoma constitute a not uncommon association.

Evidence of subclinical inflammation and an increase of flare in the anterior chamber of untreated eyes with choroidal melanoma has been demonstrated by laser photometry measurements. ${ }^{12}{ }^{13}$ The presence of flare is correlated with the size of the tumour and is higher in larger lesions. ${ }^{13}$ Clinical inflammation with anterior uveitis may be a rare presenting sign of untreated melanoma and is mainly associated with necrotic tumour. ${ }^{14}$ It can rarely be the only symptom in eyes with a small tumour that is difficult to evaluate, involving the ciliary body, for example. ${ }^{15}$

Reports of inflammatory reactions following proton beam irradiation are scarce. ${ }^{16}{ }^{17}$ They describe an inflammatory reaction essentially involving the anterior chamber and anterior vitreous, as observed in our patients. Intraocular pressure can also be elevated. ${ }^{18}$ In one case, vitreous opacities and cystoid macular oedema were also associated. ${ }^{17}$ Large published series of patients treated by proton beam or helium ions have not reported any major inflammatory reactions. ${ }^{2-41920}$ One study ${ }^{19}$ described the presence of cystoid macular oedema in the absence of radiation maculopathy, which was tentatively explained by the presence of an inflammatory reaction. The pathophysiology of the process is unclear and may involve a number of different mechanisms.

A direct radiotherapy induced lesion of the ciliary body could account for the development of inflammation, but this factor was not identified by multivariate analysis. Direct tumour involvement of the ciliary body also does not appear to be necessary as the ciliary body was not invaded by the tumour in the majority of our patients. Inflammation appears to be related to irradiation of a large percentage of the eye. This correlation with irradiation has also been described for the development of cataract and neovascular glaucoma. ${ }^{911}$

Inflammatory reactions have been rarely reported after treatment, and they are rarely correlated with histology, as they exceptionally lead to enucleation in the absence of another complication. In enucleated eyes, evidence of inflammation is usually described close to the tumour and an exceptional case of sympathetic ophthalmia has been described. ${ }^{18}$

The histology of three previously treated eyes showed a marked inflammatory reaction mainly composed of lymphocytes in the pars plana and choroid at the tumour site, but also in tumour free areas in one case. ${ }^{16}$

A comparison between treated and nontreated melanomas ${ }^{21}$ showed histological signs of inflammation associated with tumour necrosis as well as vessel damage in the treated eyes.

Tumour irradiation leads to necrosis and histological inflammatory reactions have been described in association with tumour necrosis. Spontaneous necrosis of a melanoma is often associated with an intense inflammatory reaction and anterior uveitis. ${ }^{14}$ It is possible that the inflammatory reaction present in all necrotic lesions may sometimes become clinically apparent, accounting for the appearance of ocular signs in patients with the largest lesions. Another argument suggesting that tumour necrosis is responsible for the appearance of intraocular inflammation is the lag time of 12 months after treatment. The regression patterns of melanomas after proton beam ${ }^{22}$ show that regression occurs after the first months (median 12 months). This response appears to be parallel with the appearance of inflammation seen in our patient cohort. Breakdown of the aqueous barrier induced by vessel damage, as observed in anterior segment ischaemia, is another possible explanation.

Ocular inflammation is frequent after proton beam treatment of choroidal melanoma. It usually has a favourable clinical course and this characteristic could possibly account for the limited description of this reaction in larger 
series of treated patients. It may be associated with tumour necrosis and vessel damage. The risk factors for ocular inflammation are an initial tumour height of more than $5 \mathrm{~mm}$ and irradiation of a large volume of the eye.

1 Gragoudas ES, Seddon J, Goitein M, et al. Current results of proton beam irradiation of uveal melanomas. Ophthalmology 1985;92:284-91.

2 Gragoudas ES, Seddon JM, Egan K, et al. Long-term results of proton beam irradiated uveal melanomas. Ophthalmology. 1987;94:349-53.

3 Zografos L, Perret C, Gailloud C. Conservative treatment of uveal melanoma by accelerated proton beam. In: Bornfeld N, Gragoudas E, Höpping W, et al, eds. Tumors of the eye. Proceedings of the second international symposium on diagnosis and treatment of intraocular tumors, Geneva,
Switzerland, 23-23 November 1987, Amsterdam/New Switzerland, 23-23 Novem

4 Char DH, Kroll SM, Castro J. Ten-year follow-up of helium on therapy for uveal melanoma. Am $\mathcal{f}$ Ophthalmol 1998;125:81-9.

5 Damato BE, Foulds WS. Surgical resection of choroidal melanoma. In: Ryan SJ, Ogden TE, Schachat AP, eds. Retina. 2nd ed. St Louis: Mosby-Year Book, 1994:795807.

6 Oosterhuis JA, Journee-de Korver HG, Kakebeeke-Kemme HM, et al. Transpupillary thermotherapy in choroidal melanomas. Arch Ophthalmol 1995;113:315-21.

7 Shields CL, Shields JA, Cater J, et al. Transpupillary thermotherapy for choroidal melanoma:tumor control and visual results in 100 consecutive cases. Ophthalmology 1998;105:581-90.

8 Shields CL, Shields JA, DePotter P, et al. Transpupillary thermotherapy in the management of choroidal melanom Ophthalmology 1996;103:1642-50.

9 Gragoudas ES, Egan KM, Walsh SM, et al.Lens changes after proton beam irradiation for uveal melanoma. $A m \mathcal{F}$ Ophthalmol 1995;119:157-64.
10 Guyer DR, Mukai S, Egan KM, et al. Radiation maculopathy after proton beam irradiation for choroidal melanoma. thy after proton beam irradiation

11 Foss AJ, Whelehan I, Hungerford JL, et al. Predictive factors for the development of rubeosis following proton beam radiotherapy for uveal melanoma. $\mathrm{Br} f \mathcal{f}$ Ophthalmol 1997;81:748-54.

12 Kuchle M, Schonherr U, Nguyen NX, et al. Quantitative measurement of aqueous flare and aqueous "cells" in eyes with diabetic retinopathy. Ger f Ophthalmol 1992;1:164-9.

13 Castella AP, Bercher L, Zografos L, et al. Study of the blood-aqueous barrier in choroidal melanoma. $\mathrm{Br} f$ Ophthalmol 1995;79:354-7.

14 Fraser DJ Jr, Font RL. Ocular inflammation and hemorrhage as initial manifestations of uveal malignant melanoma. Incidence and prognosis. Arch Ophthalmol 1979;97:1311-4

15 Nguyen QD, Foster CS. Ciliary body melanoma masquerading as chronic uveitis. Ocul Immunol Inflamm 1998;6: $253-6$

16 Seddon JM, Gragoudas ES, Albert DM. Ciliary body and choroidal melanomas treated by proton beam irradiation. Histopathologic study of eyes. Arch Ophthalmol 1983;101: 1402-8.

17 Ferry AP, Blair CJ, Gragoudas ES, et al. Pathologic examination of ciliary body melanoma treated with proton beam irradiation. Arch Ophthalmol 1985;103:1849-53.

18 Fries PD, Char DH, Crawford JB, et al. Sympathetic ophthalmia complicating helium ion irradiation of a choroidal melanoma. Arch Ophthalmol 1987;105:1561-4.

19 Char DH, Castro JR, Kroll SM, et al. Five-year follow-up of helium ion therapy for uveal melanoma. Arch Ophthalmol 1990;108:209-14

20 Char DH, Kroll SM, Castro J. Long-term follow-up after uveal melanoma charged particle therapy. Trans Am Ophthalmol Soc 1997;95:171-87.

21 Saornil MA, Egan KM, Gragoudas ES, et al. Histopathology of proton beam-irradiated vs enucleated uveal melanomas. Arch Ophthalmol 1992;110:1112-8.

22 Wilkes SR, Gragoudas ES. Regression patterns of uveal melanomas after proton beam irradiation. Ophthalmology 1982;89:840-4. 